\title{
Preparation and Characterization of Aligned Iron Oxide Carbon Nanotube Thin Film Acta Physica Polonica A 125, 77 (2014), ERRATUM
}

\author{
H. Hekmatara, M. Seifi* and S.M. Rozati \\ Department of Physics, Faculty of Science, University of Guilan, Rasht, Iran
}

Thin films of acid-functionalized multiwall carbon nanotubes (O-MWCNT) with different concentrations and coated O-MWCNT with $\mathrm{Fe}_{3} \mathrm{O}_{4}$ nanoparticles ( $\mathrm{MWCNT} / \mathrm{Fe}_{3} \mathrm{O}_{4}$ ) were prepared on glass substrate at $300^{\circ} \mathrm{C}$ by spray pyrolysis technique. In order to study the effect of nanotubes alignment on the physical properties of carbon nanotube films, thin film of iron oxide nanoparticles coated carbon nanotubes was deposited under magnetic field of $0.4 \mathrm{~T}$. All samples were characterized using UV-Vis spectroscopy, X-ray diffraction, scanning electron microscopy, and the Hall effect experiment. Results show that the electrical conductivity and optical transmittance of carbon nanotubes thin films depend on the concentration of carbon nanotubes and their arrangement at the films. Aligning carbon nanotubes in thin films leads to an obvious improvement in electrical and optical properties of thin films.

original DOI: 10.12693/APhysPolA.125.77

actual DOI: 10.12693/APhysPolA.125.1249

PACS: $99.10 . \mathrm{Cd}$

This article was originally published on January 2014 with an incorrect version of Fig. 1. The authors apologizes for this error. The correct version of Fig. 1 appears below.
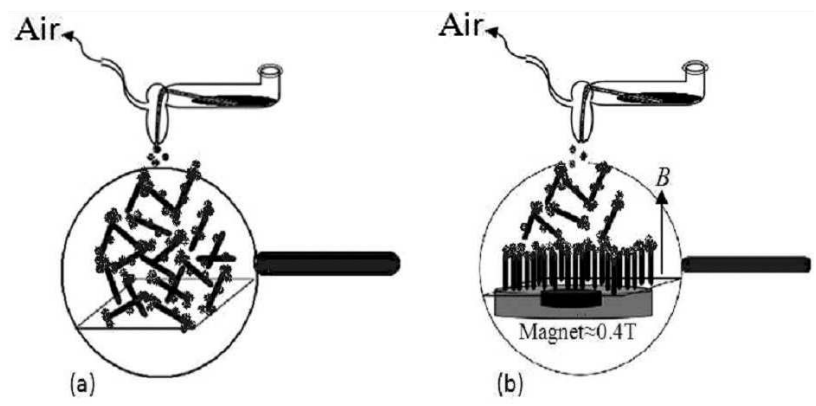

Fig. 1. Deposition processes of films that contain (a) MWCNT $/ \mathrm{Fe}_{3} \mathrm{O}_{4}$ and (b) $\mathrm{MWCNT} / \mathrm{Fe}_{3} \mathrm{O}_{4}$ in the presence of magnetic field.

*corresponding author; e-mail: m_seifi2000@yahoo.com 